\title{
Disopyramide-induced Pneumonitis, Diagnosed by Lymphocyte Stimulation Test Using Bronchoalveolar Lavage Fluid
}

\author{
Yoshihiro Yamamoto, Fumihiko Narasaki, Yohji Futsuki, Kiyoyasu Fukushima*, \\ Kazunori Tomono**, Jun-ichi KADOTA** and Shigeru KoHNO**
}

\begin{abstract}
A 72-year-old man was admitted to our hospital with fever and cough. He had been on disopyramide treatment for nine days to control cardiac arrhythmia. On admission, chest X-ray examination revealed reticulonodular opacities in both lungs, and impending respiratory failure was evident. A differential cell count of the bronchoalveolar lavage fluid (BALF) showed a marked increase of lymphocytes. A lymphocyte stimulation test (LST) for disopyramide using BALF was positive, although the test using peripheral blood was negative. This case suggests that LST using BALF is useful for the diagnosis of drug-induced pneumonitis.

(Internal Medicine 40: 775-778, 2001)
\end{abstract}

Key words: drug-induced pneumonitis, CD4/8

\section{Introduction}

Disopyramide is a Group Ia toxic drug according to Vaughan Williams' classification, and is a representative anti-arrhythmic agent commonly prescribed for various types of tachyarrhythmias. The side effects of disopyramide, which are due to its anti-cholinergic actions, include a sensation of thirst, urination disorders, and constipation. With regard to anti-arrhythmic agent-induced pneumonitis, previous studies have reported that amiodarone (Group III) can cause this type of pneumonitis (1). To our knowledge, however, no cases of disopyramide-induced pneumonitis have been reported previously. Here, we report a patient with disopyramide-induced pneumonitis. Diagnosis was established by lymphocyte stimulation test using bronchoalveolar lavage fluid (BALF).

\section{Case Report}

A 72-year-old man had the main complaints of fever and cough. He had had surgery for prostate hypertrophy in 1990 and surgical repair of a right inguinal hernia in 1993. On May 30,1998 , the patient consulted a physician for palpitation. Under a diagnosis of ventricular extrasystole, disopyramide was administered in the morning. In the evening of the same day, the patient reported high fever of at least $38^{\circ} \mathrm{C}$ and dry cough. At a local clinic, acute bronchitis was suspected. On June 3, the patient was treated with a course of oral tosufloxacin tosilate and on June 5, an intravenous drip of cefotiam dihydrochloride was started. However, no improvement was noted and the patient was referred and admitted to our hospital on June 8, 1998.

On admission, his physical examination findings were: height, $160 \mathrm{~cm}$; body weight, $59 \mathrm{~kg}$; body temperature, $37.5^{\circ} \mathrm{C}$; blood pressure, 140/80 mmHg; pulse, $80 \mathrm{bpm}$. Consciousness was clear. There was no anemia, jaundice, cyanosis or finger clubbing. Fine crackles were present bilaterally on auscultation of both lung fields. Cardiac sounds were clear, and no murmurs were heard. Palpation showed no superficial lymphadenopathy and absence of edema or exanthema. Abdominal examination was negative. There were no neurologic abnormalities. Laboratory findings on admission are shown in Table

Table 1. Laboratory Data on Admission

\begin{tabular}{lrlrll}
\hline RBC & $406 \times 10^{4} / \mu l$ & T-bil & $0.5 \mathrm{mg} / \mathrm{dl}$ & $\mathrm{Na}$ & $131 \mathrm{mEq} / l$ \\
$\mathrm{Hg}$ & $13.1 \mathrm{~g} / \mathrm{dl}$ & ZTT & $4.5 \mathrm{KU}$ & $\mathrm{K}$ & $3.7 \mathrm{mEq} / l$ \\
$\mathrm{Ht}$ & $38.3 \%$ & $\mathrm{TTT}$ & $1.2 \mathrm{KU}$ & $\mathrm{Cl}$ & $99 \mathrm{mEq} / l$ \\
WBC & $8,300 / \mu \mathrm{l}$ & $\mathrm{AST}$ & $88 \mathrm{IU} / l$ & $\mathrm{CRP}$ & $23.9 \mathrm{mg} / \mathrm{dl}$ \\
st. & $12 \%$ & $\mathrm{ALT}$ & $56 \mathrm{IU} / l$ & $\mathrm{ESR}$ & $66 \mathrm{~mm} / \mathrm{h}$ \\
seg. & $70 \%$ & $\mathrm{TP}$ & $6.7 \mathrm{~g} / \mathrm{dl}$ & $\mathrm{Ig} \mathrm{E}$ & $59 \mathrm{U} / \mathrm{ml}$ \\
Eo. & $1 \%$ & $\mathrm{Alb}$ & $3.7 \mathrm{~g} / \mathrm{dl}$ & $\mathrm{Blood}$ gases \\
Mo. & $3 \%$ & $\mathrm{LDH}$ & $628 \mathrm{IU} / l$ & $\mathrm{pH}$ & 7.477 \\
Ly. & $14 \%$ & $\mathrm{BUN}$ & $15.0 \mathrm{mg} / \mathrm{dl}$ & $\mathrm{PaO}_{2}$ & $61.3 \mathrm{torr}$ \\
Plt & $16.1 \times 10^{4} / \mu 1$ & $\mathrm{Cre}$ & $0.9 \mathrm{mg} / \mathrm{dl}$ & $\mathrm{PaCO}_{2}$ & $33.0 \mathrm{torr}$ \\
\hline
\end{tabular}

From the Department of Internal Medicine, Nagasaki Prefecture Shimabara Onsen Hospital, *the Department of Internal Medicine, Nagasaki Prefecture Tarami Hospital and **the Second Department of Internal Medicine, Nagasaki University School of Medicine, Nagasaki

Received for publication August 30, 2000; Accepted for publication January 31, 2001

Reprint requests should be addressed to Prof. Shigeru Kohno, the Second Department of Internal Medicine, Nagasaki University School of Medicine, 7-1 1chome, Sakamoto, Nagasaki 852-8501 


\section{Yамамото et al}

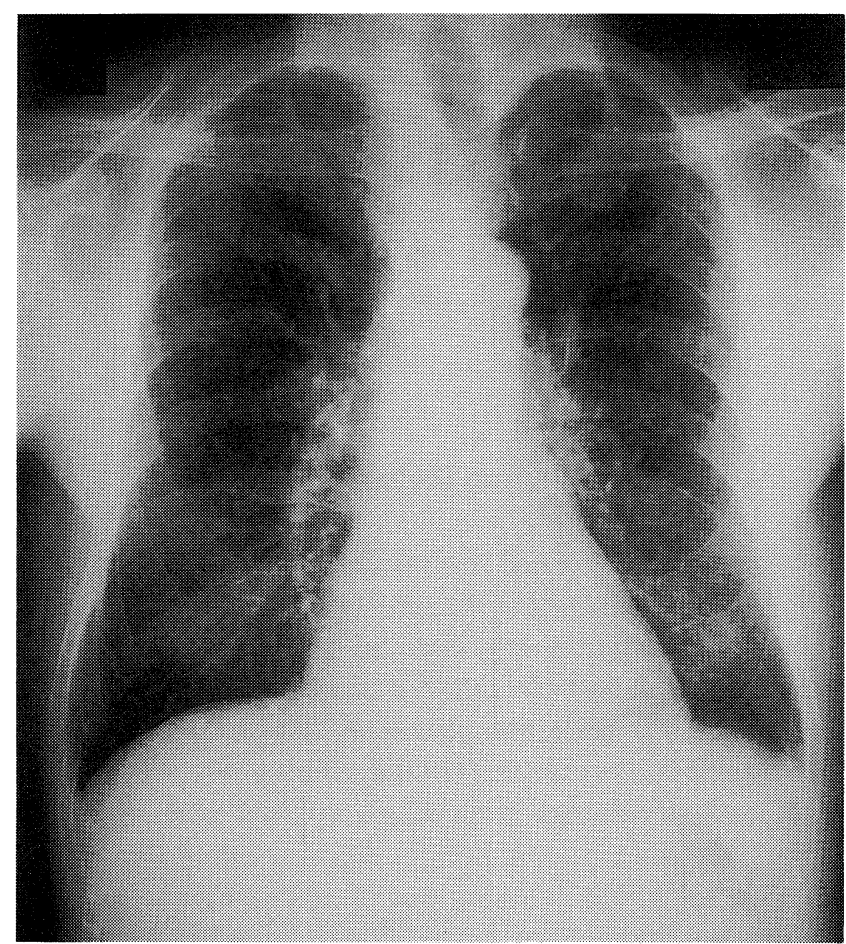

Figure 1. Chest X-ray film on admission shows diffuse reticulonodular opacities in both lungs.
1. Plain chest X-ray (Fig. 1) showed diffuse reticulonodular opacities bilaterally over the entire lungs (especially upper lung fields). Thoracic computed tomography (CT) (Fig. 2) showed centrilobular reticulonodular opacities predominantly in the upper lobes. Furthermore, a small volume of pleural effusion was noted bilaterally.

Following hospital admission, a provisional diagnosis of

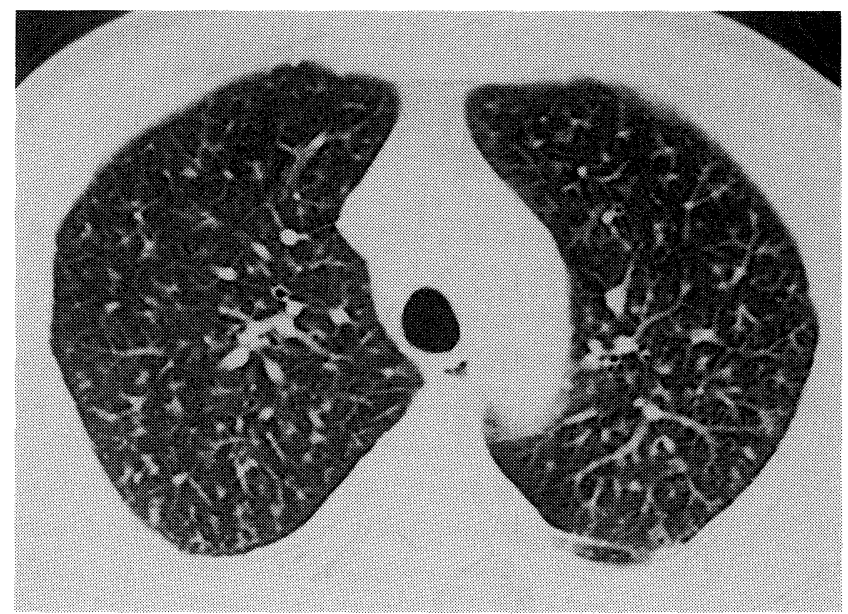

Figure 2. Chest CT on admission shows diffuse reticulonodular opacities in both lungs.

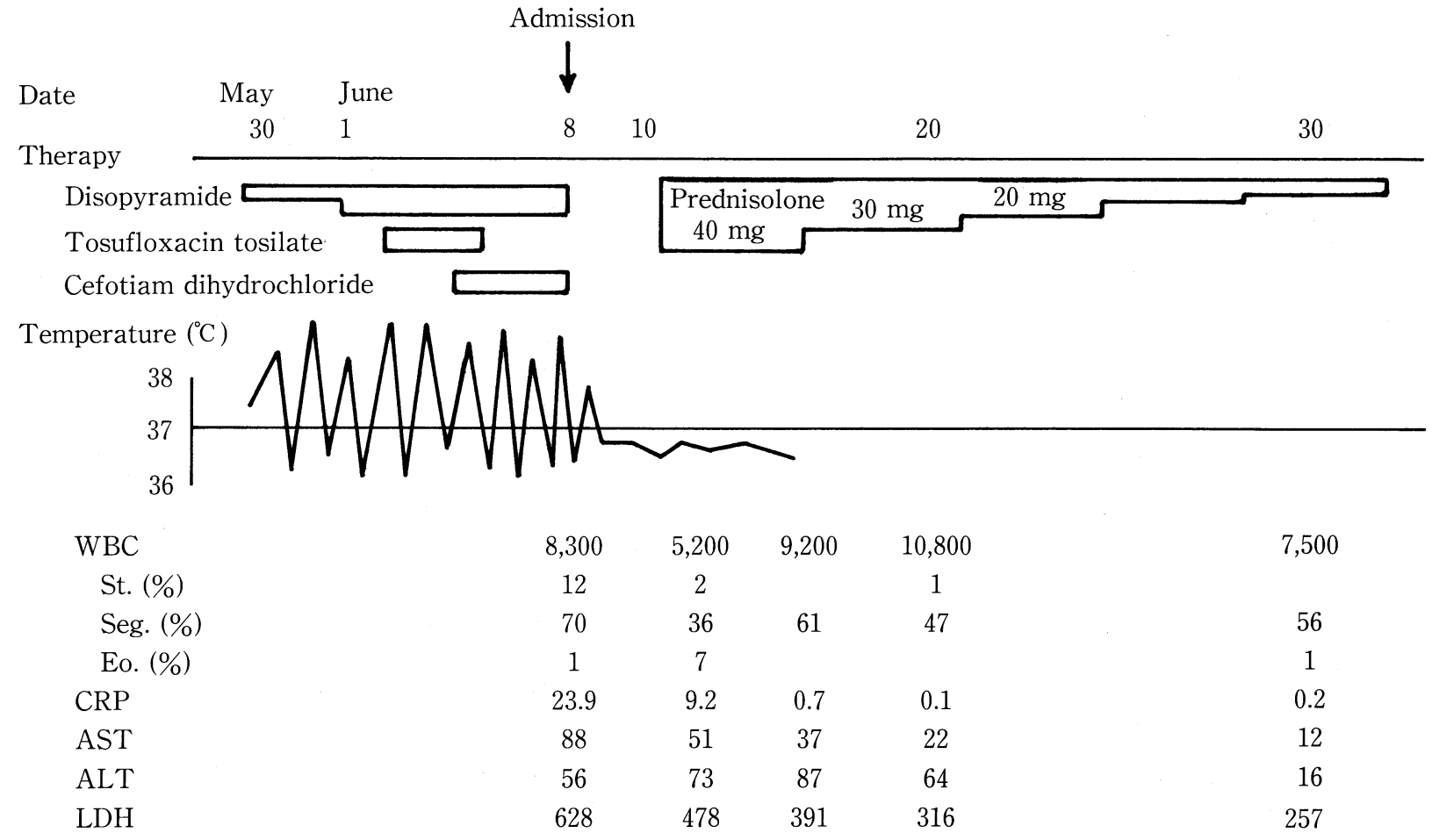

Figure 3. Clinical course. 
drug-induced pneumonitis (Fig. 3). Accordingly, both disopyramide and cefotiam dihydrochloride were discontinued. This resulted in improvement of clinical symptoms and laboratory findings, but no changes in the radiological features on the chest X-ray. On June 11, 1998, bronchoscopy was performed to make a definitive diagnosis. There were no abnormal findings within the visible range. Although bronchoalveolar lavage (BAL) examination is generally performed using BAL fluid (BALF) collected from the middle lobe, it was performed in this patient using BALF from the right $\mathbf{B}^{1} \mathbf{a}$ where the shadow, probably representing microbial infection, was sharply defined. BALF examination showed a high percentage of lymphocytes (65.19\%), and a high CD4/CD8 ratio (68.64) (Table 2). Bacteriological examination was negative for general bacteria and tuberculosis. A transbronchial lung biopsy did not reveal any abnormalities. The results of lymphocyte stimulation test (LST) are shown in Table 3. With respect to tosufloxacin tosilate and cefotiam dihydrochloride, LST could not be performed due to the insufficient number of samples. Measurements of lymphocytic subsets and LST were performed by SRL Inc (Tokyo). Based on the above findings, the diagnosis was established as disopyramide-induced pneumonitis. Serial chest X-rays continued to show no improvement in the pulmonary shadows.

Table 2. Analysis of Bronchoalveolar Lavage

\begin{tabular}{lcc}
\hline & $1998 / 6 / 11$ & $1998 / 7 / 1$ \\
\hline Recovery rate (\%) & $54.0(81 / 150 \mathrm{ml})$ & $39.3(59 / 150 \mathrm{ml})$ \\
Total cell count & $6.75 \times 10^{5}$ cells $/ \mathrm{ml}$ & $2.28 \times 10^{5}$ cells/ml \\
Analysis & & \\
Am $(\%)$ & 31.73 & 74.88 \\
Ly. $(\%)$ & 65.19 & 24.92 \\
Neut. (\%) & 3.07 & 0.18 \\
Eo. $(\%)$ & 1.00 & \\
Lymphocyte subpopulation & & 88.3 \\
CD 3 (\%) & 97.4 & 85.6 \\
CD 4 (\%) & 96.1 & 8.0 \\
CD 8 (\%) & 1.4 & 10.7 \\
CD 4/8 ratio & 68.64 & \\
\hline
\end{tabular}

Table 3. Drug Lymphocyte Stimulation Test

\begin{tabular}{lcc}
\hline & $(\mathrm{cpm})$ & $\begin{array}{c}\text { Stimulating } \\
\text { index (\%)* }\end{array}$ \\
\hline $\begin{array}{l}\text { Peripheral blood } \\
\quad \text { Disopyramide }\end{array}$ & 406 & 126 \\
$\quad$ Tosufloxacin tosilate & 477 & 148 \\
$\quad$ Cefotiam dihydrochloride & 521 & 161 \\
$\quad$ control & 322 & \\
Bronchoalveolar lavage fluid & & \\
$\quad$ Disopyramide & 381 & 241 \\
$\quad$ control & 158 & \\
\hline
\end{tabular}

*Stimulating index $(\%) \geqq 181$ : positive.
Therefore, on June 11, 1998, the patient was treated with a course of $40 \mathrm{mg} /$ day of prednisolone orally. This treatment resulted in improvement of the pulmonary shadows, and accordingly, the dose of prednisolone was gradually reduced. On June 30,1998, thoracic CT showed the persistence of only a small number of particle-like shadows. On July 1, 1998, another BAL was performed. Examination of recovered BALF showed a reduction in the percentage of lymphocytes to $24.92 \%$ and CD4/ CD8 ratio to 10.7 (Table 2). On July 8, 1998, the prednisolone treatment was discontinued and the patient was discharged from the hospital. The patient was followed up in the outpatient clinic, and to date has shown no relapse.

\section{Discussion}

The pathogeneses of drug-induced pulmonary disorders are mainly classified into cytotoxic mechanisms and non-cytotoxic mechanisms $(2,3)$. Most agents that cause cell damage are anticancer agents. Several non-cytotoxic agents can also cause pneumonitis such as antimicrobial agents, Sino-Japanese agents, and anti-arrhythmic agents (more than 100 agents). With respect to pneumonitis induced by anti-arrhythmic agents, amiodarone, is generally known to cause pneumonitis. To our knowledge, however, no cases of disopyramide-induced pneumonitis have been reported previously. The present patient may be the first case.

Types III and IV allergies are considered to be among the non-cytotoxic mechanisms. Because symptoms appeared about 6 hours after oral administration of disopyramide, it was considered that the type III allergic reaction (Arthus type), in which an immunocomplex was formed by disopyramide as the extrinsic antigen, was the more likely mechanism rather than the delayed type IV allergy reaction.

A similar disorder is hypersensitivity pneumonitis. Although analysis of the Trichosporon asahii antibody was not performed in the present patient, the marked increase in the CD4/CD8 ratio in BALF and the negative response in the environmentinduction examination argue against trichosporonosis. Other environmental factors and pathological examination ruled out hypersensitivity pneumonitis. Examination of BALF performed on the 21 st day of treatment revealed a reduction in the number of lymphocytes although the percentage of these cells was still high. This could be due to complications such as pneumoconiosis, collagen lung and atypical pneumonia, but this is unlikely considering the disease history and examination results. The reduced number of lymphocytes paralleled the improvement in clinical symptoms, suggesting that disopyramide had caused the pneumonitis. Hepatic dysfunction observed at admission gradually improved, also emphasizing the etiologic role of disopyramide in inducing pneumonitis.

To confirm the diagnosis, an inductive test using the suspected drug should be performed, although this could lead to severe reactions. Therefore, the inductive test was not performed due to the high risk in this patient who had had high fever and was hypoxemic. Previous studies have indicated that LST is useful for the diagnosis of drug-induced pneumonitis that de- 
velops through non-cytotoxic mechanisms. However, in many patients, the association of drugs cannot be ruled out, even though reactions are negative on LST with peripheral blood. In Japan, 5 patients [minocycline (4), gold preparation (5), ShoSaiko-to $(6,7)$, Sairei-to (8)] with positive findings on LST using BALF samples have been reported. The rate of positive reactions is high on LST with BALF. This may be due to the more sensitive reactions compared to LST using peripheral blood samples, since local pulmonary area-derived lymphocytes causing allergic reactions are used in the test. It is recommended that when drug-induced pneumonitis is suspected, not only LST using peripheral blood samples but also BALF and LST using BALF samples should be performed, whenever possible. However, when the inductive test cannot be made, confirmation of diagnosis of drug-induced pneumonitis can be made by examination of BAL fluid by excluding other pulmonary disorders as in our patient.

Acknowledgements: The authors thank Dr. F.G. Issa (Word-Medex, Sydney, Australia), for the critical reading and editing of the manuscript.

\section{References}

1) Coudert B, Bailly F, Lombard JN, Andre F, Camus P. Amiodarone pneumonitis. Bronchoalveolar lavage findings in 15 patients and review of the literature. Chest 102: 1005-1012, 1992.

2) Cooper JA Jr, White DA, Matthay RA. Drug-induced pulmonary disease. part I: Cytotoxic drugs. Am Rev Respir Dis 133: 321-340, 1986.

3) Cooper JA Jr, White DA, Matthay RA. Drug-induced pulmonary disease. part II: Noncytotoxic drugs. Am Rev Respir Dis 133: 488-505, 1986.

4) Shinozaki K, Hashizume I, Takiguchi Y, et al. A case of minocyclineinduced pneumonitis. J Jpn Soc Bronchol 8: 754-759, 1987 (Abstract in English).

5) Matsumura Y, Miyake A, Ishida T. A case of Gold lung with positive lymphocyte stimulation test to Gold, using bronchoalveolar lymphocytes. Jpn J Thorac Dis 30: 472-477, 1992 (Abstract in English).

6) Doi Y, Uchida K, Sekiguchi S, Tamura N, Oka T. A case of Sho-Saiko-to induced pneumonitis followed up by DLST testing BALF ( bronchoalveolar lavage fluid) findings. Nihon-Kyobu-Rinshou 55: 147-151, 1996 (Abstract in English).

7) Takada N, Arai S, Kusuhara N, et al. A case of Sho-Saiko-to-induced pneumonitis, diagnosed by lymphocyte stimulation test using bronchoalveolar lavage fluid. Jpn J Thorac Dis 31: 1163-1169, 1993 (Abstract in English)

8) Maeno T, Ubukata M, Maeno Y, et al. A case of Sairei-to-induced pneumonitis diagnosed by lymphocyte stimulation test of bronchoalveolar lavage fluid. Jpn J Thorac Dis 35: 1347-1351, 1997 (Abstract in English). 